\title{
Addressing engineering threshold concepts in an African university of technology
}

\section{Leanri van Heerden ${ }^{1}$, Nicolaas Luwes ${ }^{2}$}

${ }^{1}$ Centre for Innovation in Learning and Teaching, Central University of Technology, Free State, South Africa, ${ }^{2}$ Department of Electrical and Computer Engineering, Central University of Technology, Free State, South Africa.

\begin{abstract}
Learning new skills isn't only for the benefit of passing the exam but being able to apply those skills in a productive way. One cannot learn before one understands which is why student understanding is a priority for facilitators. This becomes especially important in threshold concepts where a student will be unable to progress to the next stage before the threshold concept is mastered, but facilitators do not focus on pedagogy as they rely on the support of instructional designers. This explorative paper looks at student perceptions of their understanding of the threshold concept in electrical engineering, logic gates, after completing a lesson designed using the proposed ten-step activity plan. The activity plan is derived from the learning theories of Gagne, Biggs, Vygotsky and Gibson. A sample of 18 students completed an online survey that focused on their acquiring of skills relating to logic gates, truth tables and Boolean algebra. Results showed a positive experience with $88.89 \%$ of participants indicating that they left the lesson with a good understanding of the threshold concept. This ten-step activity plan can assist to close the gap between instructional designer and facilitator to design threshold concept lessons based on sound learning theory.
\end{abstract}

Keywords: threshold concepts; learning theory; instructional design; student comprehension. 


\section{Introduction}

Those who study the philosophy of pedagogy, believe that understanding precedes learning (Peel, 2017). These philosophers understand that comprehension and learning are not synonyms, but rather two forces working together for the acquisition of knowledge. Those who devote their lives to the study of pedagogy are always looking for new and better ways of instilling a passion for learning in others. Higher Education institutions devote whole departments to support facilitators in this regard.

The issue with these support/facilitator relationships is that the parties involved often do not speak the same language. Very little of the facilitator's time is allocated for topics like adult learning, memory or transfer of learning (Halpern \& Hakel, 2003) so if not assisted they must find their own way. This is truer for addressing threshold concepts that need more care in the planning phase. For the instructional designer this causes a new dilemma. To assist every facilitator from scratch is a heavy burden and to pick up and intervene in existing planning can be equally frustrating.

This paper proposes a template activity plan for the use of facilitators when designing threshold concept learning activities. The activity plan is derived from sound learning theories and will assist the facilitator and instructional designer in speaking the same language when it comes to designing threshold concept learning activities.

This paper will firstly underpin the research with a literature review on threshold concepts, the nature of understanding and learning theories. The activity plan will then be discussed followed by the methods and results. Finally, a conclusion will be drawn with implications and possibilities for further research.

\section{Literature review}

A threshold concept is a notion within a discipline that, when mastered, lets a student experience a shift in their understanding of the subject matter. It is difficult for a student to move forward with new material if the preceding threshold concept is not comprehended. Students find threshold concepts frightening or intimidating and the experience will vary from student to student (Rattray, 2016). Students are not the only ones who find these concepts intimidating as the facilitators share responsibility in the journey to understanding.

Understanding of any concept in higher education requires a degree of reading and listening comprehension skills. According to Durrell (1969) "a weakness in either ability is detrimental to learning in most subject areas." So, when dealing with a more complex threshold concept the facilitator must be vigilant for comprehension in their student. Testing is one way of seeing who did not grasp the concept, but by then they may have already fallen behind a great deal as understanding of threshold concepts is needed to achieve the next outcome. Therefore, 
facilitators underpin their lessons with sound theories that encourage learning to enable students to reach intended goals.

There are a great many theoretical approaches and constructions for learning and facilitators mainly select an approach based on subject matter and learning environment. In essence, learning is a process that permanently changes the adeptness of a certain skill that is not prompted by normal biological maturation (Illeris, 2018), instead it is prompted by intervention in this case from the facilitator. As facilitators are often subject specialists and have not necessarily tested their teaching practices using a systematic approach (Halpern \& Hakel, 2003), they may need to source assistance from support departments in the university equipped to deal with their needs.

\section{Context}

e-Learning support for academic staff at the CUT falls to the e-Learning and Educational Technology unit which includes instructional design assistance. There are two learning designers who not only support academia with the interface design of their blended courses - 1477 registered on the LMS in 2018 - but also the instructional design using tried and tested learning theories.

Logic gates are one of the concepts in electrical engineering that needs to be mastered early on to be able to progress to subsequent concepts. One might call this the building block of integrated circuit design which is why the authors identified it for this paper.

\section{Ten-step activity plan}

The proposed activity plan follows 10 steps and is derived from the learning theories; Constructive Alignment (Biggs, 2003), Social Constructivism (Vygotsky, 1962), Gagne's Events of Instruction (Gagne, 1985) and Affordance (Gibson, 1966) .

\subsection{The steps}

Following are the steps for this activity plan:

1. Hook challenge - Derived from Gagne's Events of Instruction where the first step is to gain the student's attention, the Hook challenge is a quick and fun activity related to the content of the learning unit. It must use skills students already have or can teach themselves with relative ease.

2. Inform students of the outcomes - Derived from Gagne and Biggs, by letting the students know early on where they are headed, they can not only better plan but also know exactly what is expected of them. 
3. Group Discussion: Outcomes - This one combines Gagne and Vygotsky. Students are to discuss the outcomes in a group and share any similar past experiences to stimulate recall of prior learning.

4. Theory - Here the facilitator works through the theory, allowing students to participate and providing all the resources.

5. Group Discussion: Content - Students to discuss the theory and help each other make sense of it. At this stage, it is the facilitator's purpose to encourage new avenues of thinking and weaving the conversation into a positive learning experience.

6. Applied Activity - Students apply the theory in a real-world type simulation interacting with the environment as derived from Gibson. Facilitator should provide guidance.

7. Rubric - The facilitator should constantly refer to the rubric whilst giving feedback. That is why it's important that the rubric criteria are aligned with the outcomes and very specific as derived from Biggs' Constructive Alignment.

8. Presentation of Results - Here students present their results to their peers.

9. Feedback and Critique - Facilitator provides final feedback and constructively critiques the student.

10. Exploration Challenge - An activity that applies the same skills but to a new context should be designed to enhance retention and transfer of the new skills in line with Gagne.

\subsection{The template in action}

The below activity plan designs a lesson on the electrical engineering threshold concept, logic gates. The template consists of four parts. The column for the learning outcomes (A) lists the behaviours (green) and criterions (blue) that must be met to master the threshold concept. The second column (B) shows the ten steps as the teaching and learning activities. These translate into 7 assessment tasks as noted in the third column (C) where the facilitator lets the instructional designer get an idea of the lesson being planned. The final column (D) is where the facilitator draws up the rubric. This is a very important step as the facilitator must ensure that the behaviours in the learning outcomes align with the criteria in the rubric. In the same way should the criterion in the learning outcomes align with the competency levels in the rubric. This way quality is ensured as the outcomes are aligned with the assessment method and students know exactly what is expected of them.

For a lesson to be designed, the facilitator merely follows the ten steps and completes the template. Then can the instructional designer support in the design as they have a better understanding of the lesson, even in the absence of discipline specific knowledge. 


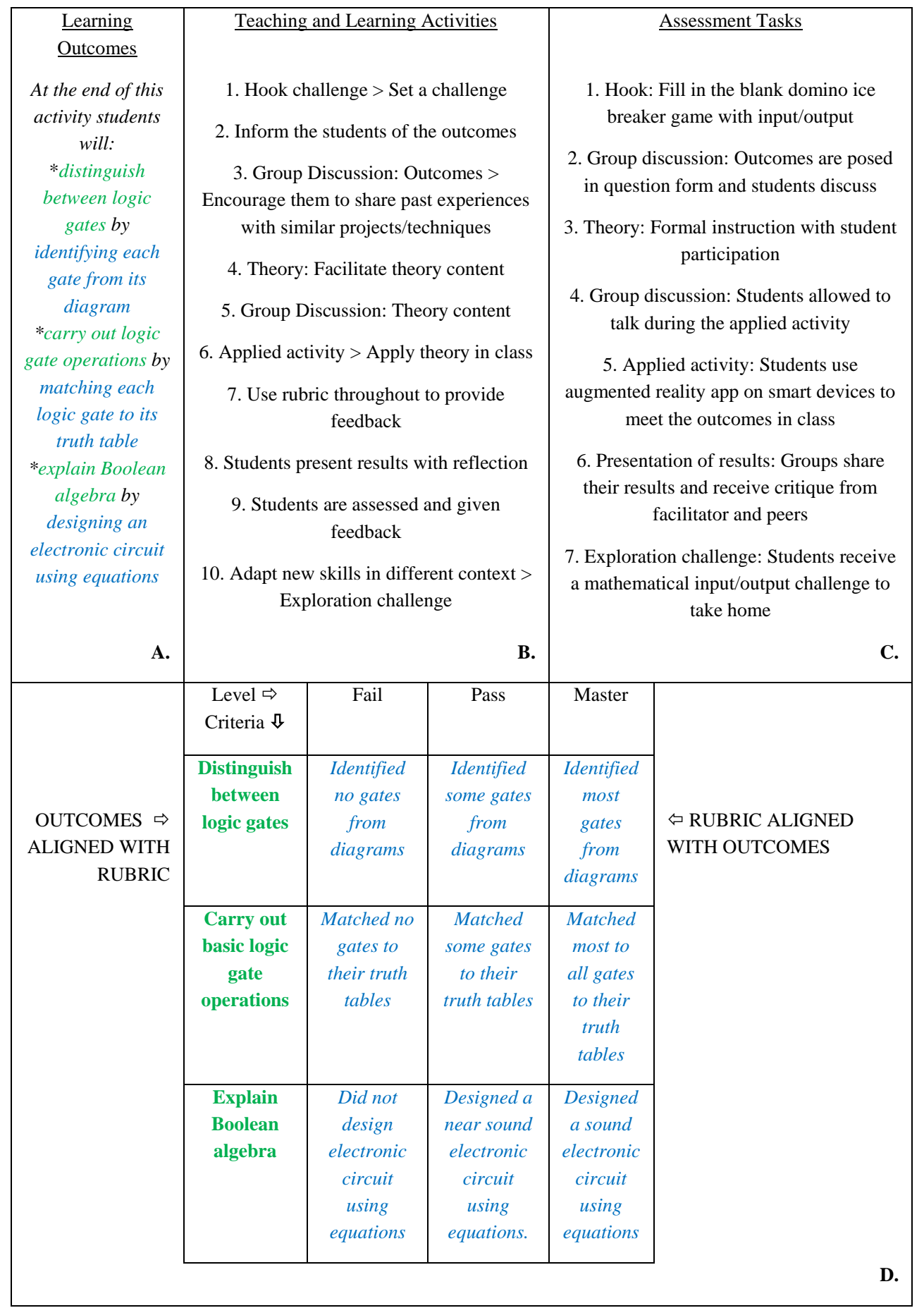

Figure 1. The activity plan for the logic gates lesson in the subject Logic Design III. 


\section{Methodology}

Students were asked to complete a survey, using the online survey tool QuestionPro, questioning them on their experience of a lesson designed using the proposed activity plan. This type of exploratory design assists researchers in shedding some light on unexplored terrain (De Vos, Strydom, Fouche, \& Delport, 2011). The resulting data was then quantified in a descriptive analysis to further expand on the experience (Foster, 2016).

The target population of the study was the 52 students enrolled for Logic Design III of which 18 completed the survey. A five-point Likert scale ranging from Not at all to Extremely was used to ascertain the participant perspectives and to ensure adequate coverage. To strengthen content validity questions focused on the activities completed during the lesson.

\section{Results}

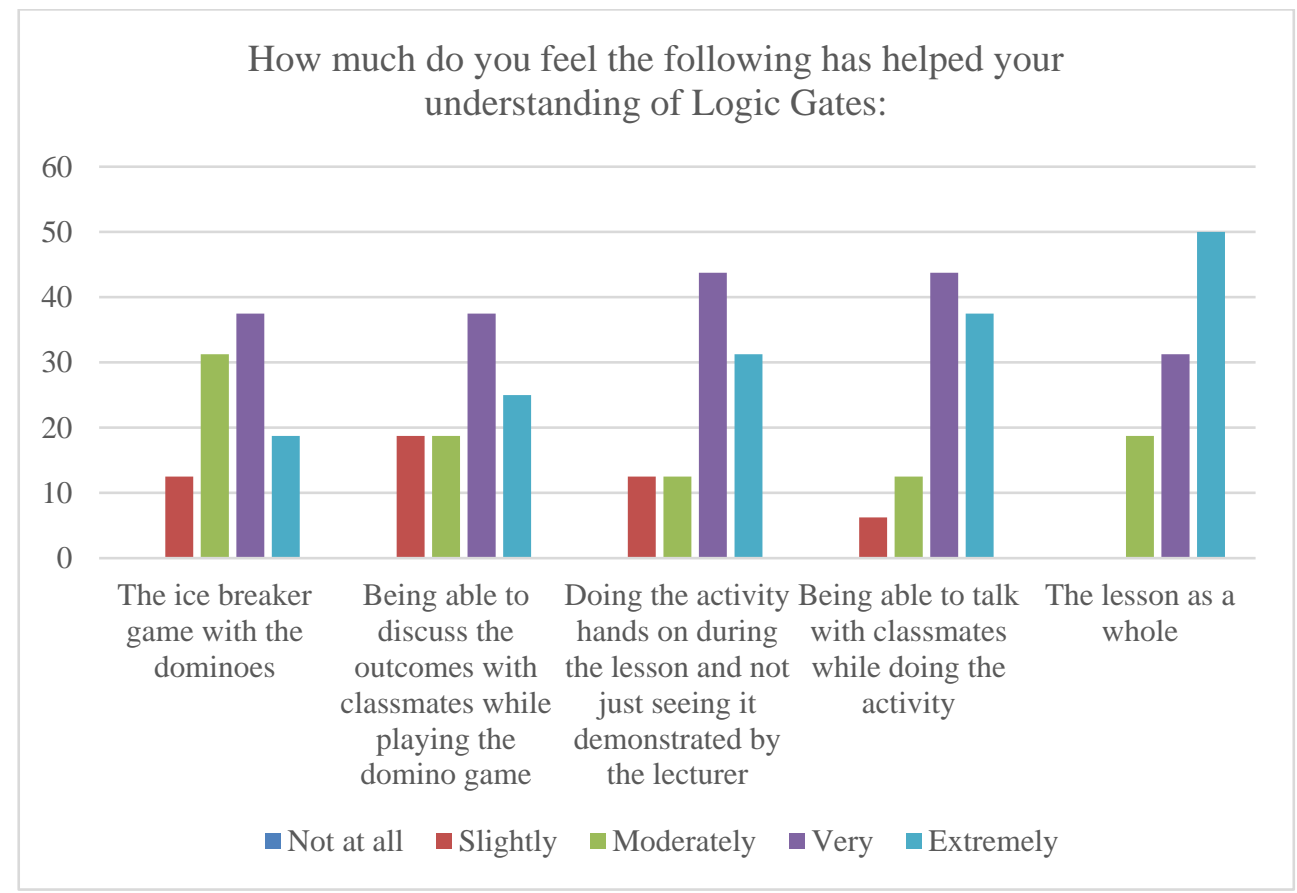

Figure 2. Participants' perspectives on the efficacy of the activity.

Overall, participants felt that the lesson designed using the activity plan has helped their understanding of this threshold concept. When asked about the specific steps $56.25 \%$ (Very $-37.5 \%$; Extremely - 18.75\%) felt positive towards the ice breaker game, $56.25 \%$ (Very $37.5 \%$; Extremely $-25 \%$ ) benefited from the discussion on the lesson outcomes, $75 \%$ (Very $-43.75 \%$; Extremely $-31.25 \%$ ) felt that they mastered the hands-on activity and $81.25 \%$ 
(Very $-43.75 \%$; Extremely $-37.5 \%$ ) felt that being able to talk to peers while doing the activity helped them better understand the concept. Finally, when asked about the lesson as a whole, $81.25 \%$ (Very - 31.25\%; Extremely - 50\%) felt that they understand the concept better after experiencing the lesson designed with the activity plan.

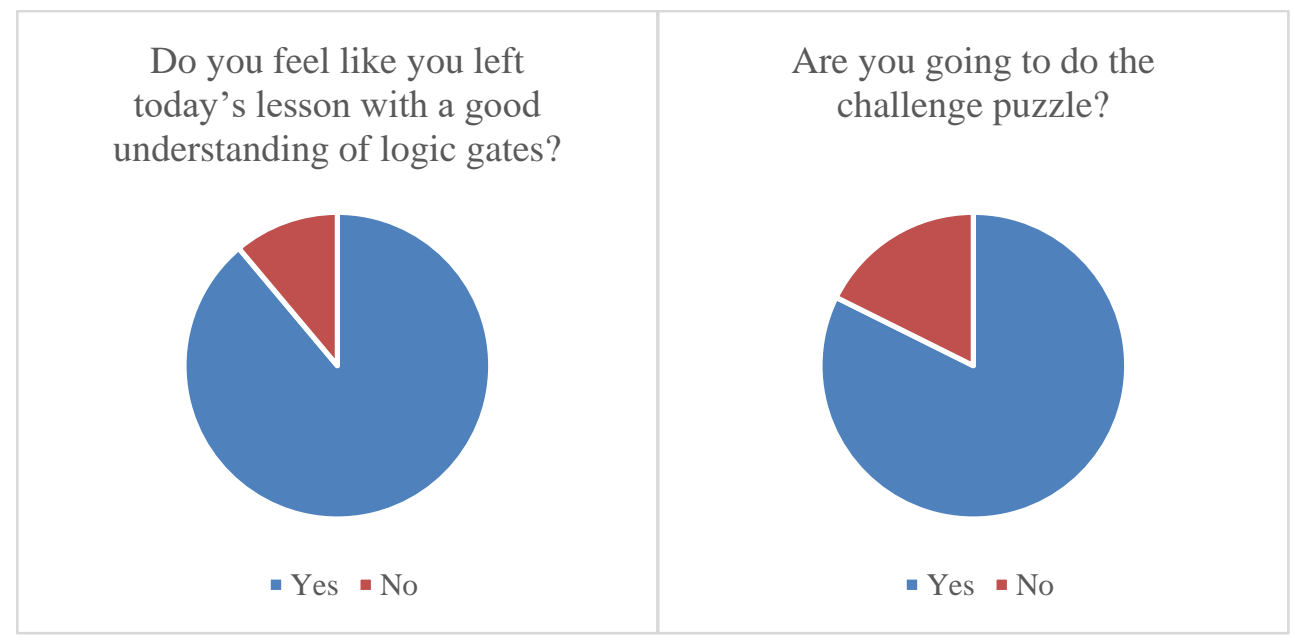

Figure 3. Participants' perspectives on their understanding of logic gates post lesson (left) and whether or not they were going to attempt the challenge puzzle (right).

When asked if they felt they left the lesson with a good understanding of logic gates $88.89 \%$ of participants answered Yes which indicates a very successful intervention. A further query into whether or not they were going to attempt the challenge puzzle, $82.35 \%$ indicated that they will give it a go, which shows the lesson has created an interest to explore the topic further.

\section{Conclusion}

This paper aimed to address the threshold concept of logic gates in electrical engineering by designing a lesson using the proposed ten-step activity plan. This template is meant to narrow the gap between facilitator and instructional designer as it lets them speak the same language. The literature review showed that a threshold concept shifts a student's understanding of a subject and that the facilitator shares in the responsibility of making that understanding happen. The proposed ten-step activity plan is derived from the learning theories of Gagne, Biggs, Vygotsky and Gibson and was used to design a lesson for the 52 students enrolled in Logic Design III. Eighteen of these students participated in the survey and provided positive results with $88.89 \%$ indicating that the lesson left them with a good understanding of logic gates. 
The positive results of the survey indicate a successful intervention and that the use of a structured template will enable the instructional designer to better assist facilitators when designing lessons for threshold concepts. This template can be adapted for blended and online lessons as well as be used to design whole modules provided that an extra step of reflection is added to keep in touch with students. This template will not only improve the relationship between instructional designers and facilitators, but also leave facilitators confident that they are fulfilling their responsibility to help students with understanding of threshold concepts.

\section{References}

Biggs, J. (2003). Biggs, J (2003): Aligning Teaching and Assessment to Curriculum Objectives, (Imaginative Curriculum Project, LTSN Generic Centre). Teaching and Learning in HIgher Education: New Trends and Innovations, 1-9.

Bolarinwa, O. A. (2015). Principles and methods of validity and reliability testing of questionnaires used in social and health science researches. Nigerian Postgraduate Medical Journal, 22(4), 195-201.

De Vos, A., Strydom, H., Fouche, C. B., \& Delport, C. S. (2011). Research at grass roots: For social sciences and human service professions. Pretoria: Van Schaik Publishers.

Durrell, D. D. (1969). Listening Comprehension versus Reading Comprehension. Journal of Reading, 12(6), 455-460.

Foster, C. W. (2016). The lived persistent meaning of abrupt, permanent separation from a black, female nanny during early childhood: A phenomenological psychological study. Saybrook University.

Gagne, R. (1985). The Conditions of Learning (4 ed.). New York: Holt, Rinehart \& Winston.

Gibson, J. J. (1966). The Senses Considered as Perceptual Systems. London: Allen and Unwin.

Illeris, K. (2018). A comprehensive understanding of human learning. In K. Illeris, Contemporary Theories of Learning: Learning theorists... in their own words (2 ed., pp. 8-9). New York: Routledge.

Rattray, J. (2016). Affective dimensions in liminality. In R. Land, J. H. Meyer, \& M. T. Flanagan, Threshold concepts in practice (pp. 67-76). Rotterdam: Sense Publishers.

Vygotsky, L. S. (1962). Thought and Language. Massachusetts: MIT Press and John Wiley and Sons. 